\title{
Effect of New Superhard Phases Formation on Properties of Composite Processed by SHS
}

\author{
Lembit Kommel $^{1,}$, , Toomas Tamm², b , Raido Metsvahi ${ }^{1, c}$ \\ ${ }^{1}$ Department of Materials Engineering, Tallinn University of Technology, Ehitajate tee 5, 19086 \\ Tallinn, Estonia \\ 2Department of Chemistry, Tallinn University of Technology, Akadeemia tee 15, 19086 Tallinn, \\ Estonia \\ alembit.kommel@ttu.ee, btamm@yki.ttu.ee, 'raido.metsvahi@ttu.ee
}

Keywords: SHS, CMC, c-BC ${ }_{2} \mathrm{~N}$, wear, friction, hardness

\begin{abstract}
A composite was produced from initial powder mixture of $\mathrm{B}_{4} \mathrm{C}(70 \mathrm{wt} . \%)$ and $\mathrm{Al}(30 \mathrm{wt}$. $\%$ ) with WC-Co additives introduced during ball-milling and acting as catalysts by self-propagating high-temperature synthesis and followed by heat treatment of raw samples under gaseous nitrogen flow at $650,800,1000,1150$ and $1450{ }^{\circ} \mathrm{C}$, respectively. Formation of different new superhard phases was detected via XRD investigation and analysis of microstructures. Micromechanical properties were tested by nanoindentation. The tribological behavior in dry sliding conditions of the composite was investigated using the ball-on-disk technique against alumina balls. The friction coefficient of the composite increased and wear rate decreased with formation of $c-\mathrm{BC}_{2} \mathrm{~N}, c-\mathrm{BN}$, $\mathrm{B}_{13} \mathrm{C}_{2}, \mathrm{~W}_{2} \mathrm{~B}_{5}, \mathrm{Al}_{3} \mathrm{BC}, \mathrm{AlN}$, etc. contents during heat treatment at increased temperatures.
\end{abstract}

\section{Introduction}

Creation of wear resistant composite materials based on $\mathrm{WC}, \mathrm{TiC}, \mathrm{CrC}$, etc. and produced via powder metallurgy techniques [1] has seen significant developments in the last decades. These hard metals and cermets, with hard reinforcement carbides and $\mathrm{CoNi}$ binder phase, have superior mechanical, physical and chemical properties that make them especially attractive for use as tribomaterials in a wide range of industrial applications [2]. It is well known, that basic tribological mechanisms are two-body and three-body abrasion, contact fatigue, thermal fatigue, etc. The improved properties of materials (based on $\mathrm{WC}, \mathrm{TiC}$ and $\mathrm{CrC}$ ) include good wear resistance and low friction coefficient on the surfaces of metal forming tools [3]. The Al-based light-weight metalmatrix composites (MMC) with minor hard reinforcements like carbon nanotubes (CNTs) [4], carbon nanofibers (CNFs) [5] and boron carbide $\left(\mathrm{B}_{4} \mathrm{C}\right)$ [6] are being developed as engineering materials. It is well known that the friction and wear of engineering materials depend on the testing environment (nitrogen, water, salt), grain size (coarse-grained, ultrafine-grained, nanocrystalline), chemical composition (high purity, with alloying elements, metal matrix or ceramic matrix composites, etc.), hardness, processing history, etc.

Usually the hard phases are introduced in composite via powder metallurgy. In other cases chemistry-based methods are used to enhance the mechanical properties of composites. It is generally assumed that temperatures at least $2000{ }^{\circ} \mathrm{C}$ and pressures of $25 \mathrm{GPa}$ [7-10] are required for formation of cubic boron carbon nitride $\left(c-\mathrm{BC}_{2} \mathrm{~N}\right)$, whereas in the experimental investigation [11] the use of temperatures between $650{ }^{\circ} \mathrm{C}$ and $1450{ }^{\circ} \mathrm{C}$ with pressures up to $120 \mathrm{MPa}$ is reported. It has been shown in [12]; however, that cobalt and nickel may act as catalysts in reactions involving boron-carbon nitride at lower temperatures. In this paper we also investigate the possibilities of such reactions occurring in the course of the present experiments.

Boron, nitrogen and carbon form a continuum of phases with varying composition and properties, including the sought-after superhard $c-\mathrm{BC}_{2} \mathrm{~N}$. Chemical reactions leading to formation of this phase involve gradual atomic substitutions in the lattice, combined with phase transitions. The possible chemical routes to the destination and the potential role of aluminum and cobalt additives remain unclear at this stage. It is proposed that initially a change in the structure of $\mathrm{B}_{4} \mathrm{C}$ takes place, followed by insertion of nitrogen. The process may be catalyzed by the cobalt atoms. It is possible 
to get new ceramic phases in composite by self-propagating high temperature synthesis (SHS) [13]. The light-weight metal matrix composites (MMC) for defense components in military aviation were produced via SHS and followed heat treatment in zirconium oxide $\left(\mathrm{Zr}_{2} \mathrm{O}_{3}\right)$ flux at in the air [14]. The mean Rockwell hardness of $80 \pm 5$ HRA was obtained. The formation of new ceramic phases via transformation of solid phase at high temperatures and their influence on the different fracture mechanisms of the composite were studied in [15].

The aim of the present report is to study the mechanism of formation of new superhard phases $(c-$ $\mathrm{BC}_{2} \mathrm{~N}, c-\mathrm{BN}, \mathrm{B}_{13} \mathrm{C}$, etc) during ball-milling, SHS and compression (for densification) and followed heat treatment under low-pressure nitrogen gas at high temperatures and the influence of these phases on mechanical and tribological properties of the composite.

\section{Experimental}

The raw composite was produced by using a low cost capsule technique of self-propagating high temperature synthesis (SHS) $[10,11,13-15]$. The initial mixture consisted of powdered boron carbide $\left(\mathrm{B}_{4} \mathrm{C}-70\right.$ wt. \%), aluminum (Al-27 wt. \%) and copper $\left(\mathrm{Cu} \sim 3\right.$ wt. \%). The $\mathrm{B}_{4} \mathrm{C}$ powder was industrial grade $(\mathrm{H} 8)$ with grain size in range of 4.2-74.7 $\mu \mathrm{m}$ (average $17.3 \mu \mathrm{m}$ ) containing also free carbon $(\mathrm{C})$, small amount of quartz $\left(\mathrm{SiO}_{2}\right)$ and boron carbide $\left(\mathrm{B}_{13} \mathrm{C}_{2}\right)$. The pure aluminum powder was PA-4 (GOST 6058-73) containing 0.35 wt. \% Fe, 0.4 wt. \% Si, and 0.02 wt. \% Cu impurities. WC-Co impurities as catalyst [12] were introduced during 20 hours of ball-milling of the powder with $70 \mathrm{wt}$. $\%$ of $\mathrm{B}_{4} \mathrm{C}$. The mill chamber and balls were manufactured from WC-Co $(\mathrm{Co}=8 \mathrm{wt} . \%)$ hard metal. Depending on the increase of $\mathrm{B}_{4} \mathrm{C}$ content and milling time the content of WC-Co in composites also increased as a result of wear during ball-milling [11]. The WC-Co content was found to be about $8 \mathrm{wt} . \%$ in this study. Additionally, a small amount $(\leq 3 \mathrm{wt}$. \%) of copper $(\mathrm{Cu})$ was added to increase the wetting of $\mathrm{B}_{4} \mathrm{C}$ crystallites with $\mathrm{Al}$ binder during the process [16].

The mixed powder compositions were placed into a steel container [14]. The steel capsules were heated in furnace with low heating rate of $1-2{ }^{\circ} \mathrm{C} / \mathrm{min}$ from $600{ }^{\circ} \mathrm{C}$ to $800{ }^{\circ} \mathrm{C}$ to initiation of the SHS process in powder mixture. For better densification of heated products the subsequent pressing on hydraulic press with compression stress of $\sim 120 \mathrm{MPa}$ was conducted immediately after SHS. After compaction, the raw samples were removed from the steel container by cutting it open. Heat treatment was conducted in vacuum furnace (RED DEVIL vacuum furnace WEBB 107, USA). The main parameters of the regimes were the vacuum of $10^{-2}$ mbar, followed by low flow nitrogen $\left(\mathrm{N}_{2}\right)$ in the surrounding atmosphere under chamber pressure of 0.2 bar (+3PSI), with temperature increase rate of $2{ }^{\circ} \mathrm{C} / \mathrm{min}$, and duration at maximum temperature about two hours, then followed by cool-down time of $\sim 15 \mathrm{~h}$. The temperatures of heat treatment were $650,800,1000,1150$ and 1450 ${ }^{\circ} \mathrm{C}$, respectively. Because the heating rate was constant, the duration of heat treatment was increased for the highest temperatures, accordingly.

The obtained composite samples were subjected to microstructural studies with the light optical (Nikon CX) and scanning electron (Zeiss EVO MA-15) microscopes. Powder X-ray diffraction (Bruker AXS, D5005) was used to analyze stages of formation of the hard refractory compounds as the function of the processing steps, and chemical composition of the initial powders, as well as the SHS-processed raw products, and samples heat treated at different sintering temperatures. The micromechanical properties, such as nanohardness and elastic modulus of the constituents of composites, were characterized using the nanoindentation device of NanoTest NTX testing centre (Micro Materials Ltd.). A trigonal Berkovich diamond tip with a three-sided pyramid apex angle of $142.3^{\circ}$ and radius of $100 \mathrm{~nm}$ was used for the measurements. Nanioindentation was conducted on diamond-polished surface of samples under load of 20, 100 and $500 \mathrm{mN}$ for 100 indents with step of 10 and $15 \mu \mathrm{m}$, respectively. Mechanical properties were automatically calculated from the loaddisplacement curves according to Oliver-Pharr method [17]. The phases at the indented sites were identified with SEM pictures. The tribological behavior of composites was tested by tribometer CETR (Bruker) UMT2 in dry sliding conditions of ball-on-disk technique against alumina $\left(\mathrm{Al}_{2} \mathrm{O}_{3}\right)$ balls with diameter of $3 \mathrm{~mm}$. The wear test parameters were: load $=2 \mathrm{~N}$, distance $=2 \mathrm{~mm}$, frequency $=10 \mathrm{~Hz}$, velocity $=40 \mathrm{~mm} / \mathrm{sec}$, time $=10 \mathrm{~min}$. For volume wear calculation the crosssections area with back-and-forth wear tracks was measured by Mahr Pertohometer PGK 120 Concept 7.21. The friction coefficient was obtained automatically. 


\section{Results and discussion}

In Fig. 1 the wear track (a) and measured cross-section of wear track (b) for the sample after heat treatment at $1450{ }^{\circ} \mathrm{C}$ are presented. The wear track length is $\sim 2.5 \mathrm{~mm}$. The SHS-processed raw metal-matrix composite shows relatively low friction coefficient ranging up to $\sim 0.23$. During heat treatment at $650{ }^{\circ} \mathrm{C}$ it increased up to $\sim 0.84$ and up to $\sim 0.98$ (after heat treatment at $1450{ }^{\circ} \mathrm{C}$ ) (Fig. 2 , a). The wear track cross-section was measured and it was equal to $F=2537.3 \mu \mathrm{m}^{2}$. As shown, the volume wear has opposite evolution (Fig. 2, b). Such evolution of friction coefficient and volume wear as well as wear rate depends on change of hard phase's content in the composites. Nanohardness values of the phases varied significantly, from $\sim 5 \mathrm{GPa}$ up to $\sim 100 \mathrm{GPa}$ (Fig. 3). The collected mean nanohardness (measured under load of $500 \mathrm{mN}$ ) of heat treated composites was $39 \pm 2 \mathrm{GPa}$. This indicates that the superhard ceramic phase $c-\mathrm{BN}_{2} \mathrm{C}$ has very high wear resistant properties. As shown in Fig. 4 these hardest compounds are presented in the shape of protrusions on wear surface. The height of protrusion in wear traces is about 3-5 $\mu \mathrm{m}$ while in diamond grinded surface it is only about $1-1.5 \mu \mathrm{m}$. The measured diameter of these equal-axis superhard phases is about $15 \mu \mathrm{m}$. The results of X-ray investigation are presented in Fig. 5 for different heat treatment temperatures, respectively.
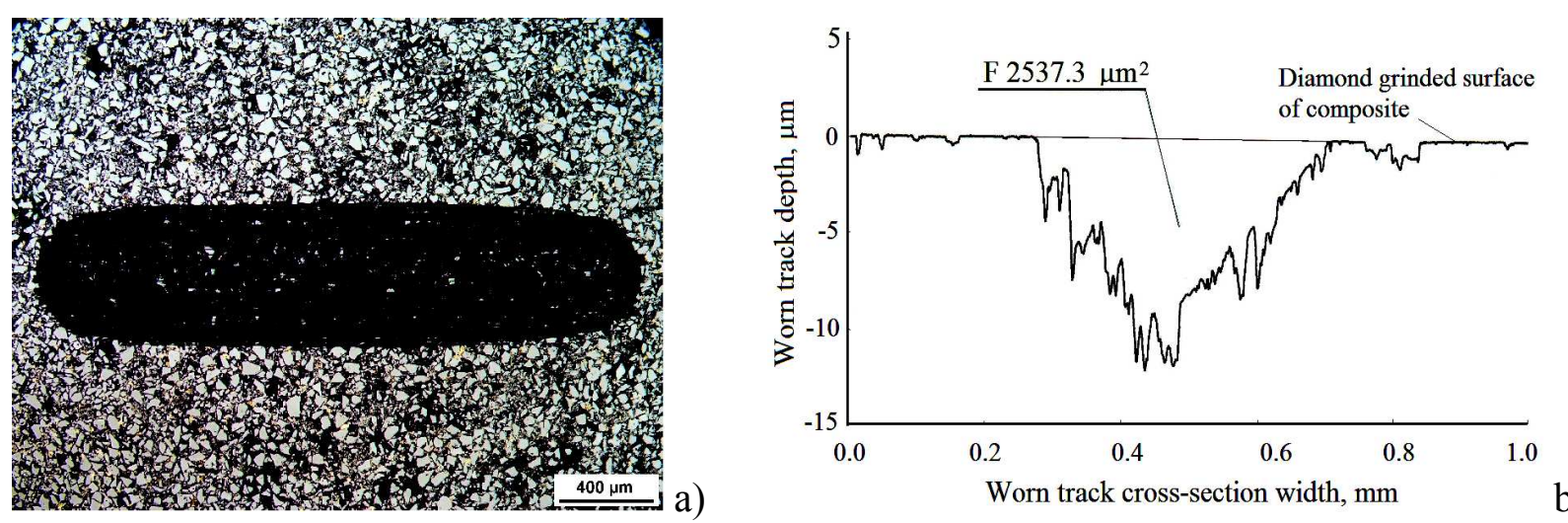

Fig. 1. Wear track (a) and measured cross-section of wear track (b) of SHS-composite (with 70 wt. $\%$ of $\mathrm{B}_{4} \mathrm{C}$ in initial compound) followed heat treatment at $800{ }^{\circ} \mathrm{C}$ (a) and at $1450{ }^{\circ} \mathrm{C}(\mathrm{b})$.
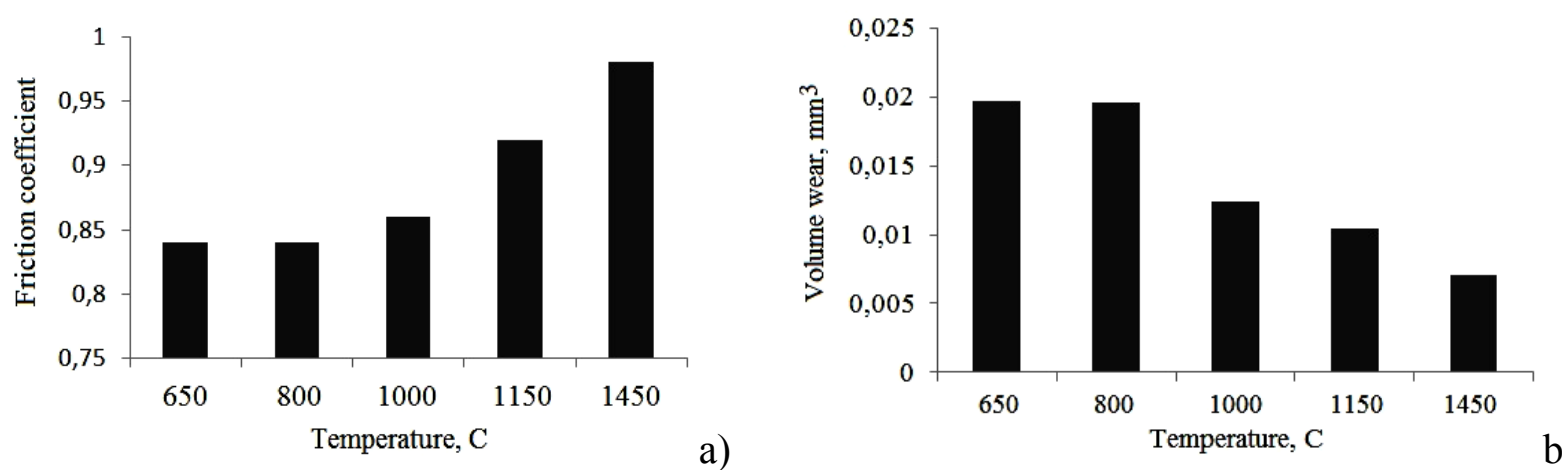

Fig. 2. Friction coefficient (a) and volume wear (b) of composite (with 70 wt. $\%$ of $\mathrm{B}_{4} \mathrm{C}$ in initial compound) for different temperatures of heat treatment in nitrogen atmosphere. 


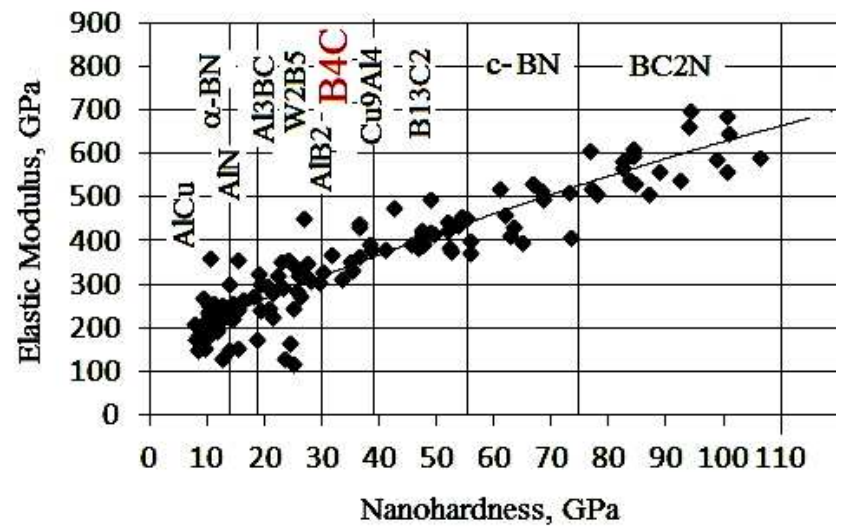

Fig. 3. The new phases formed $\left(\mathrm{B}_{4} \mathrm{C}\right.$, initial phase, red color) hardness and elastic modulus values of the composite as detected by X-ray (Fig. 5) and nanoindentation $[11,17]$ techniques.
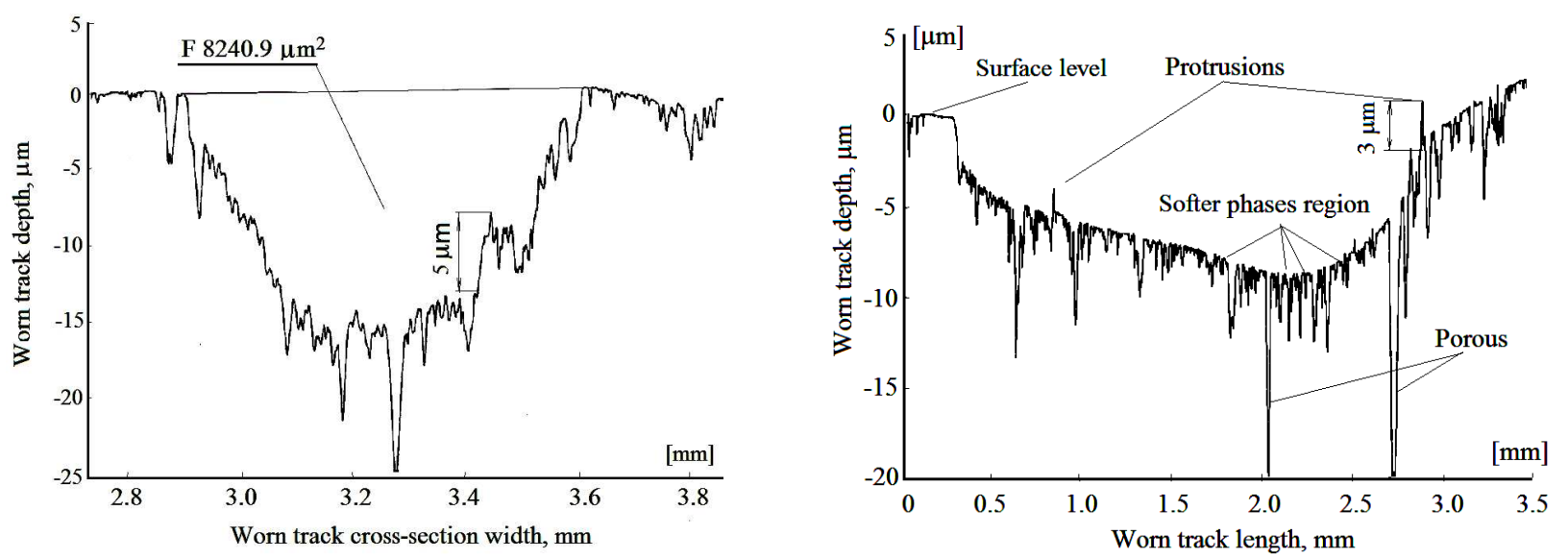

Fig. 4. Protrusions (in wear tracks of tribological testing) of superhard $c-\mathrm{BC}_{2} \mathrm{~N}$ phase in crosssection (a) and in longitudinal direction (b) of tacks, respectively.

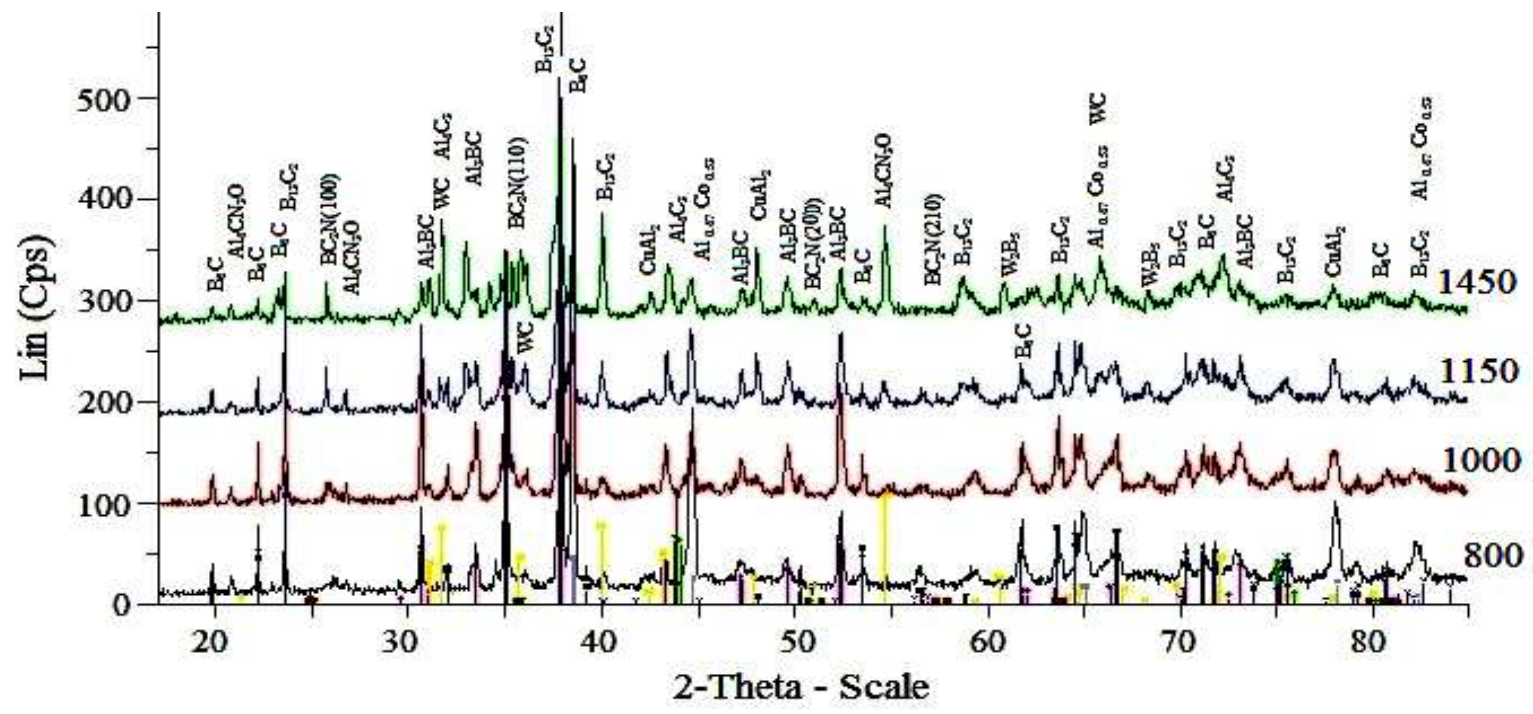

Fig. 5. X-ray diffraction curves of composite (with initial composition $\mathrm{B}_{4} \mathrm{C}-70$ wt. $\%$, Al-27 wt. \% and $\mathrm{Cu}-3$ wt.\%) processed via ball-milling, SHS, compression and heat treated at 800, 1000, 1150 and $1450{ }^{\circ} \mathrm{C}$ under low-pressure $\mathrm{N}_{2}$, respectively. 
The results of XRD investigation show that during ball-milling some WC-Co was inserted into the powder. This content was identical for all samples as the milling time was $20 \mathrm{~h}$ and $\mathrm{B}_{4} \mathrm{C} / \mathrm{Al}-\mathrm{Cu}$ content was identical before milling. During SHS processing, $\mathrm{B}_{4} \mathrm{C}$ was transformed into $\mathrm{B}_{13} \mathrm{C}_{2}$ up to the amount of $\sim 44.8 \mathrm{wt} . \%$. This icosahedral boron compound [18] has an elevated hardness $H_{v}=$ 44-45 GPa. The summarized mean nanohardness of composites increased to $H_{v}=39 \pm 2 \mathrm{GPa}$ (HRA $80 \pm 2$ on Rockwell scale). The composite contains small amounts of Al-binder phase and thus may be classified as a metal matrix composite (MMC). The binder contains tungsten carbide (WC) and formation of tungsten aluminum carbide $\left(\mathrm{W}_{0.8} \mathrm{Al}_{0.2} \mathrm{C}_{0.8}\right)$ and aluminum cobalt $\left(\mathrm{Al}_{0.47} \mathrm{Co}_{0.53}\right)$ intermetallic compound is also observed. These changes in composition took place at temperatures 650-800 ${ }^{\circ} \mathrm{C}$. The composites which were heated at these temperatures have identical wear coefficient and volume wear (see Fig. 2). At that stage of processing the composites show a stabile density equal to $2.38 \mathrm{~g} / \mathrm{cm}^{3}$. At increased temperatures above $1150{ }^{\circ} \mathrm{C}$ the new superhard phases were formed and density decreased to $2.33 \mathrm{~g} / \mathrm{cm}^{3}$ and porosity increased, respectively. Compared to hard metal WC-Co [1] the density of $\mathrm{MMC}$ is about 6.2 times lower. Heat treatment at elevated temperatures leads to formation of new compounds (Fig. 5): $c-\mathrm{BC}_{2} \mathrm{~N}, c-\mathrm{BN}, \mathrm{W}_{2} \mathrm{~B}_{5}, \mathrm{Al}_{3} \mathrm{BC}, \mathrm{AlN}$, $\mathrm{CuAl}_{2}, \mathrm{Al}_{4} \mathrm{CN}_{3} \mathrm{O}$, etc. with high hardness and elastic modulus (Fig. 3). The $\mathrm{Al}$ has reacted with $\mathrm{B}$, $\mathrm{Cu}, \mathrm{Si}, \mathrm{N}$, etc. and the free $\mathrm{C}$-content decreased as the temperature increased. As a result the ceramic matrix composite (CMC) was formed. As the $c-\mathrm{BC}_{2} \mathrm{~N}$ has the highest hardness (Fig. 3) and high wear resistance during wear test in the worn surface the protrusions with high of up to $5 \mu \mathrm{m}$ were formed (see Fig. 4), respectively. This also brought about the increase of surface roughness and friction coefficient (Fig. 2, a). The wear mechanism of the composite is abrasion [1-6]. The volume wear (Fig. 2, b) of composite decreased as the material hardened (see Fig. 3). The hardening of composite takes place because $\mathrm{B}_{4} \mathrm{C}$ was transformed into $\mathrm{B}_{13} \mathrm{C}_{2}$ and the new superhard ceramic and intermetallic phases were formed on basis of the initial $\mathrm{Al}$ binder.

\section{Conclusions}

In this experimental work we studied, by means of a variety of methods, the chemical composition, mechanical and tribological properties of a $\mathrm{MMC}$ and $\mathrm{CMC}$ processed from $\mathrm{B}_{4} \mathrm{C} / \mathrm{Al}$ powder via ball-milling, SHS and compression techniques followed by heat treatment under nitrogen flow at temperatures of $800,1000,1150$ and $1450{ }^{\circ} \mathrm{C}$, respectively. During ball-milling the concentration of WC-Co was increased up to $\sim 8 \mathrm{wt} . \%$ in the powder content. The WC-Co as a wear product and as catalyst decreased the temperatures necessary to form new superhard phases like $c-\mathrm{BC}_{2} \mathrm{~N}, c-\mathrm{BN}$, $\mathrm{W}_{2} \mathrm{~B}_{5}$, etc. from $2200{ }^{\circ} \mathrm{C}$ to $1450{ }^{\circ} \mathrm{C}$. It was established that the transformation of $\mathrm{B}_{4} \mathrm{C}$ to $\mathrm{B}_{13} \mathrm{C}_{2}$ takes place during the SHS process. The other hard phases were formed mainly during heat treatment under nitrogen atmosphere at elevated temperatures. Because the composite has superhard phases with very different micromechanical properties (high hardness and wear resistance and, consequently, surface with high roughness) the volume wear as well as wear rate were decreased but friction coefficient was increased. The friction coefficient increased through increase of the $c$ $\mathrm{BC}_{2} \mathrm{~N}$ precipitates content in composite. The hardness of the new formed carbides and intermetallides has important effect on the mechanical and tribological properties of the composites. As an example of application, these composites are useful for the brake blocks manufacturing, because these are light-weight with high friction coefficient and high wear resistance, both of which are beneficial in this application.

\section{Acknowledgements:}

The authors would like to acknowledge support from Estonian Ministry of Education and Science and Estonian Science Foundation (target financial scheme SF0140062s08 and grant nr. 8472). The support and vision of Drs. M. Antonov, E. Kimmari and R. Traksmaa are greatly appreciated. 


\section{References}

[1] J. Pirso, M. Viljus, K. Juhani, S. Letunovitš, Two-body dry abrasive of cermets, Wear 266 (2009) 21-29.

[2] P. Montmitonnet, Introduction to tribology in manufacturing processes, Wear 286-287 (2012) 12.

[3] P. Karlsson, A. Gåård, P. Krakhmalev, J. Bergström, Galling resistance and wear mechanisms for cold-work tool steels in lubricated sliding against high strength stainless steel sheets, Wear 286287 (2012) 92-97.

[4] D.-S. Lim, D.-H.You, H.-J.Choi, S.-H.Lim, H. Jang, Effect of CNT distribution on tribological behavior of alumina-CNT composites, Wear 259 (2005) 539-544

[5] A. Borrell, R. Torrecillas, V.G. Rocha, A. Fernández, V. Bonache, M.D. Salvador, Effect of CNFs content on tribological behavior of spark plasma sintering ceramic-CNFs composites, Wear 274-275 (2012) 94-99.

[6] E.M. Sharifi, F. Karimzadeh, M.H. Enayati, Fabrication and evaluation of mechanical and tribological properties of boron carbide reinforced aluminum matrix nanocomposites, Materials \& Design 32 (2011) 3263-3271.

[7] M. Tang, D. He, W. Wang, H. Wang, C. Xu, F. Li, J. Guan, superhard solid solution of diamond and cubic boron nitride, Scripta Materialia 66 (2012) 781-784.

[8] V.L. Solozhenko, S.N. Dib, N.V. Novikov, Mechanical properties of cubic BC2N, a new superhard phase, Diamond and Related Materials 10 (2001) 2228-2231.

[9] K. Yuge, A. Seko, Y. Koyama, F. Oba, I. Tanaka, First-principles-based phase diagram of the cubic BNC ternary system, Physical Review B 77 (2008) 094121.

[10] V.A. Bunin, I.P. Borovinskaya, M. Yu. Senkovenko, V.I. Ponomarev, T.I. Ignat'eva, Properties of boron carbonitride prepared by self-propagating high-temperature synthesis, Inorganic Materials 39-4 (2003) 357-361.

[11] L. Kommel, R. Metsvahi, M. Viljus, E. Kimmari, K. Kolju, R. Traksmaa, Design of superhard c-BC ${ }_{2} \mathrm{~N}$-precipitates in $\mathrm{B}_{4} \mathrm{C} / \mathrm{Al}$-composites through SHS and heat treatment, $8^{\text {th }}$ Int. DAAAM Baltic Conf. 19-21 April 2012, Tallinn, Estonia, pp. 645-650.

[12] T. Sasaki, M. Akaishi, S. Yamaoka, Y. Fujiki, T. Oikawa, Simultaneous crystallization of diamond and cubic boron nitride from the graphite relative $\mathrm{BC}_{2} \mathrm{~N}$ under high pressure/high temperature conditions: Chemistry of Materials 5 (1993) 695-699.

[13] A.G. Merzhanov, 40 years of SHS: a lucky start of a scientific discovery, ISMAN, Russia, 2012.

[14] L. Kommel, USSR Patent 1,836,190 A3. (1991).

[15] L. Kommel, E. Kimmari, Solid phase's transformations in boron carbide based composites during heat treatment. TTP, Solid State Phenomena138 (2008) 175-180.

[16] P.S. Kislij, M.A. Kuzenkova, N.I. Bodnaruk, B.L. Grabchuk, Boron Carbide, Naukova Dumka, Kiev, 1988 (in Russian).

[17] Information on http://www.micromaterials.net/Hardness_Scale_Conversion.asp.

[18] A.N. Enyashin, A.L. Ivanovskii, Structural, elastic, and electronic properties of icosahedral boron subcarbides (B12C3, B13C2), subnitride B12N2 and suboxide B12O2 from data of SCCDFTB calculations, Physics of the Solid State, 53-8 (2011) 1569-1574. 